\title{
A Proposed ASEAN Disaster Response, Training and Logistic Centre Enhancing Regional Governance in Disaster Management
}

\author{
Allen Yuhung Lai · Jingwei Alex He \\ Teck Boon Tan $\cdot$ Kai Hong Phua
}

Published online: 31 March 2009

(C) Springer-Verlag 2009

\begin{abstract}
The Southeast Asian region is remarkably vulnerable to natural disasters which repeatedly cause devastations to both human lives and properties. However, current disaster relief efforts have not lived up to the high standards. Even worse is that humanitarian efforts have been frequently frustrated by the rejections from national authorities under the name of "sovereignty". All these problems necessitate a widely accepted, politically neutral, well coordinated and effectively governed organization within the region. We, hereby propose a Disaster Response Training and Logistic Centre under the umbrella of the Association of Southeast Asian Nations (ASEAN), which aims to mitigate the devastation of disasters, to provide accurate relief assessment, and training for relief team on a regular basis, and to allocate and mobilize humanitarian aid. The Centre will be endorsed through an agreement by all ASEAN governments. The philosophy underpinning the organization reflects a regional approach whereby stronger government involvement and regional integration in disaster relief is indispensable in the context of the Southeast Asian region.
\end{abstract}

Keywords Response - Training - Logistics · Southeast Asia ·

Disaster management $\cdot$ Disaster relief

\section{JEL Classification N25 $\cdot \mathrm{O} 54$}

A. Y. Lai · J. A. He · T. B. Tan · K. H. Phua $(\bowtie)$

Lee Kuan Yew School of Public Policy, National University of Singapore, Singapore, Singapore e-mail: spppkh@nus.edu.sg
A. Y. Lai
e-mail: allen@nus.edu.sg
J. A. He
e-mail: jingweihe@nus.edu.sg
T. B. Tan
e-mail: tanteckboon@nus.edu.sg 


\section{Introduction}

This research paper provides a conceptual framework for enhancing regional governance in disaster management. Currently, a number of key factors limit the capacity of international disaster relief agencies in Asia to provide effective disaster relief and recovery. Ranging from political, cultural, legal and technical dimensions, these factors often result in poorly executed relief operations. If these factors can be overcome, disaster relief efforts will undoubtedly be better coordinated and more importantly, more lives will be saved due to the timely delivery of much-needed aid.

Motivated by the need to improve the current system of disaster relief in Asia, we set out not only to conceptualize but to operationalize as well the key features of an effective regional disaster relief organization. The challenges that limit the capacity of international disaster relief agencies in Asia to provide effective disaster relief are significant; however, this paper demonstrates that many of these factors are indeed surmountable.

It has only been 5 years since a number of Asian countries were devastated by the Asian tsunami, and the timeliness of our findings is again underscored by recent disasters in Sichuan, China and Myanmar. However, these three disasters are not isolated events but rather part of a rising trend in the number of reported natural disasters (see Figs. 1, 2). While the reasons for this increase in the number of reported natural disasters are unclear, the need for more effective and better coordinated disaster relief is beyond doubt.

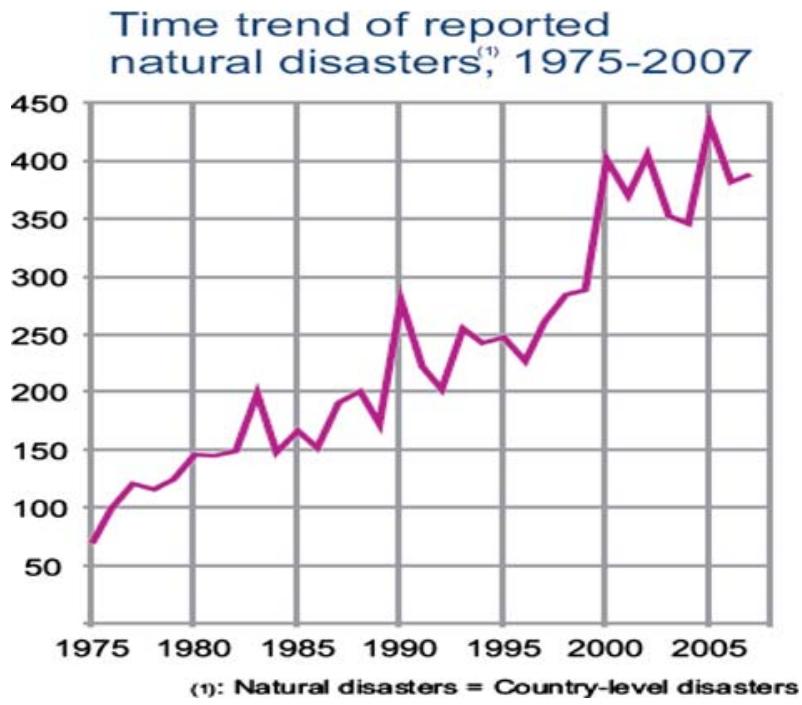

Fig. 1 Number of disasters in time trend. Source: EM-DAT, OFDA/CRED International Disaster Database (Legend: EM-DAT Emergency Events Database, OFDA Office for Foreign Disaster Assistance, CRED Centre for Research on the Epidemiology of Disaster) 
Fig. 2 Causality of natural disaster by different continents. Source: EM-DAT, OFDA/ CRED International Disaster Database (Legend: EM-DAT Emergency Events Database, OFDA Office for Foreign Disaster Assistance, CRED Centre for Research on the Epidemiology of Disaster)
Percentage of People Killed by Natural Disaster from 2000 to 2006

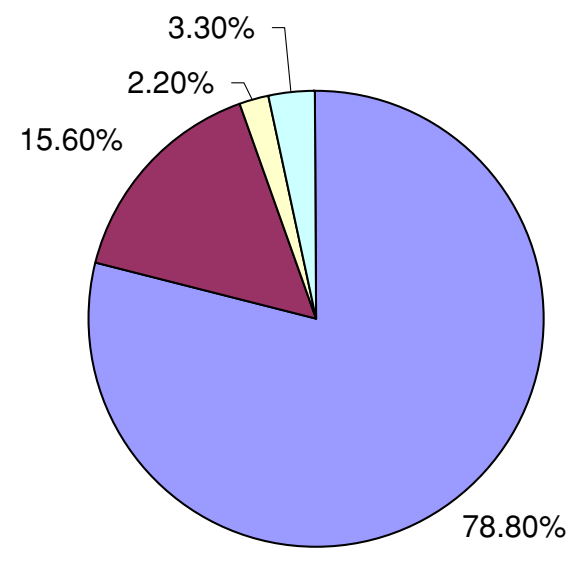

Asia $\square$ Europe $\square$ Africa $\square$ Americas

\section{A Tale of Two Disasters: Sichuan Earthquake and Cyclone Nargis}

Most recently, the world was appalled when it witnessed the overwhelming destruction in Sichuan province, China, after it was struck by a devastating earthquake. Measuring more than 8.0 on the Richter scale, the 2008 Sichuan earthquake was ranked as one of the most severe that China has ever experienced. And to make the rescue effort in the aftermath even more challenging, the disaster area continued to be rocked by aftershocks for at least 2 months. According to official Chinese figures, almost 70,000 were killed and 400,000 were listed as either injured or missing as a result of the 12 May earthquake. Economic losses also amounted to hundreds of millions of dollars.

Equally shocking was the devastation brought on by Cyclone Nargis in Myanmar. Entire townships were destroyed and for a few days, most communications channels between Myanmar and the outside world were cut off. It is estimated that more than 130,000 were killed and thousands remained missing. In fact, the destruction wrought by the 2 May cyclone was recorded as one of the worst in the history of Myanmar.

In the aftermath of the Sichuan earthquake and Cyclone Nargis, there was an immediate outpour of sympathy from the international community. Foreign governments and civil society groups were swift in offering their assistance, and international rescue teams were readied to be dispatched to the disaster areas.

In China, the government's response to the Sichuan earthquake was speedy and largely commendable. Indeed, the relief effort was well-coordinated overall. In addition, the Chinese government did not reject foreign assistance when the enormity of the devastation became clear. As a matter of fact, foreign assistance contributed an important role to the overall relief effort. Moreover, instead of 
shutting out the international media, the Chinese government actually went to great lengths to showcase the relief effort to the world. Indeed, the level of transparency exercised by the Chinese government in the aftermath of the Sichuan earthquake was in stark contrast to how it handled the SARS crisis in 2003 when outbreaks of the deadly illness were covered up by local governments. If there was a silver lining to the SARS episode in China, it was that the Chinese government learned (the hard way) the importance of good governance when dealing with disasters.

The story in Myanmar in the aftermath of Cyclone Nargis was diametrically different. At first, the Burmese military junta was wholly unresponsive to international requests for greater transparency in the aftermath of Cyclone Nargis. And when the junta finally reported the death toll, it was grossly under-reported to minimize the political fallout. Even more frustrating for the international community, foreign request to help in the relief effort was denied even when it became clear that thousands had perished and thousands more could be saved. When foreign aid was finally allowed into Myanmar after much international pressure, the relief effort itself was poorly coordinated and badly executed due to bad practices and a general lack of capacity.

Two countries wrecked by disasters but the responses cannot be more different.

\section{The Need for Better Coordination}

The cases of China and Myanmar demonstrated the need for enhanced coordination, capacity building, and transparency. Even more importantly, the timely delivery of aid can often mean the difference between life and death for disaster victims. If good global governance is the panacea of disaster management, why can relief assistance not be accessed efficiently to the affected country? Is there a need to modify the current global relief network in which it can be decentralized as a regional approach? Central to this paper is the core belief that effective disaster relief should not be denied to those that need it the most within the region.

Currently, disaster relief agencies in the Southeast Asian region face a number of key challenges that limit their capacity to respond effectively to disasters. Chief among the challenges is the practice of states invoking sovereignty to keep out foreign relief agencies. Indeed, relief agencies (such as the Red Cross) cannot have access to a disaster area without prior approval from the government of the disasterstruck country. Regardless of the severity of a disaster or the number of victims waiting to be rescued, state sovereignty cannot be superseded (International Federation of Red Cross and Red Crescent Societies 2005a, b). State sovereignty and humanitarian intervention are two concepts that, unless reconciled, will continue to limit the effectiveness of relief agencies.

Typically, relief agencies encounter two different sets of problems associated with the state's claims to sovereignty. The first set of problems occurs during the initial phase of a disaster relief operation and the second set of problems occurs during the implementation phase of a disaster relief operation.

During the initial phase of a disaster relief operation, the government of the disaster-struck country retains the right to deny relief agencies access to its 
territories, especially if the affected areas are fraught with conflict. In such a situation, relief agencies have little recourse to international legal arrangements to gain priority access to disaster areas or compel the government to grant access (Fisher 2007) For example in 2008 Cyclone Nargis, the humanitarian aid has been long obstructed by the Myanmar ruling junta which has been criticised by turning a natural disaster into a "man-made catastrophe" by blocking foreign aid efforts. In addition, the initial relief work in Aceh Indonesia during the 2004 Asian Tsunami was constrained because of local political conflict and religious resistance from receiving aid. These two cases illustrated how humanitarian assistance can be subject to affected countries' sensitive agenda.

The second main stumbling block that hampers disaster relief operations is the lack of support from the government of the country struck by disaster (Rowlands et al. 2006). This lack of support-in personnel, equipment, logistics, intelligence, etc.-can only result in poor coordination between relief agencies and the local government which ultimately degrades the effectiveness of the entire relief operation (Overseas Development Institute 1996). In Aceh, Director of the Rehabilitation and Reconstruction Agency Dr. Kuntoro Mangkusubroto recalled that during the immediate aftermath of the Asian Tsunami in 2004, relief agencies sent unnecessary supplies (such as noodles, skirts and blankets) when the affected people needed sarongs, tents, sanitary pads, and crackers. Thirteen hundred containers of donated materials sat at once in Medan's harbortown but the broken road network had not been repaired (Mangkusubroto 2005).

On the other hand, relief agencies are constrained by a number of endogenous factors that can often limit their operational effectiveness. Firstly, because relief agencies are funded by a number of countries, they lack the autonomy to make decisions independent of the donor countries. Indeed, relief agencies in general have little or no say in where and when to conduct in their relief operations. David Rieff argued that relief operations can only be enhanced when relief agencies retains greater autonomy.

At the same time, relief operations can often be counter-productive when there is a greater deal of competition and tensions between relief agencies-this is the so called "beauty contest phenomenon". Competition among different relief agencies can be very strong especially when they try to "show-off" their relief efforts to the world in order to gain recognition for their efforts (International Federation of Red Cross and Red Crescent Societies 2005a, b). To some extent, some competition is beneficial to disaster victims in the sense that it drives relief agencies to perform better. However, it is often the case that excessive competition between relief agencies leads to tensions between them and counter-productive behaviours (Christoplos 2006). Indeed, there are anecdotal evidences to suggest that relief agencies can compete with each other so excessively during joint operations that their conduct is analogous to that of beauty contestants (Wickramage 2007). In the wake of Tsunami, for example, too many organizations dividing up territory between them, competing to fly their own flags, dogged the Tsunami's aftermath (Tay and Paige 2006). In a donor "beauty contest", world leaders announced spectacular aid pledges, regardless of the actual needs or capacities of affected communities.

According to a global review conducted by UNDP on disaster risk reduction, regional and sub-regional organizations in the Hyogo Framework are regarded as 
important elements to monitor and report processes, but this role to date has not been well developed. The current relief agencies have been criticized for their existing contingency plans across countries that do not include recovery and rehabilitation elements in the post-disaster periods. In addition, another key challenge arising from an analysis of country reporting under the Hyogo Framework Priority is that mismatch between national-level efforts to strengthen institutional and legislative systems for preparedness.

When disasters strike, local civil society groups are often the ones that gain immediate access to the affected areas. The strengths and resilience of the local community should be acknowledged. Encouraging active community involvement in the recovery process is an internationally accepted principle in disaster recovery management (Australia Emergency Manual Disaster Recovery 1996). Unfortunately, many of these relief groups generally lack the expertise to execute the relief operation (SPHERE Project 2004). In fact, except for funds, many local relief agencies have limited experience and expertise to conduct relief operations. This lack of expertise often leads to another human tragedy when relief aid cannot be disbursed to those who needed it the most. It is mandatory to set up a humanitarian network to avert human rights violations, to dampen inequities in aid distribution, to enhance accountability and coordination of aid, and to leverage community participation in reconstruction (Weinstein et al. 2007).

This section has discussed some of the justifications for the establishment of a regional disaster relief centre to enhance the effectiveness and efficiency of the disaster management system that is currently in place. In sum, the current disaster management system is constrained and limited by a number of key factors. Firstly, it does not have the political clout to compel governments of disaster-stricken countries to grant relief agencies access to disaster affected areas. On the other hand, relief agencies themselves are constrained by endogenous factors. Indeed, many relief agencies lack the capacity and expertise to conduct relief operations effectively. Moreover, competition amongst relief agencies has limited coordination between them.

Given the problems with the existing disaster management system, the next section of this paper outlines the framework of a regional disaster relief centre under the auspices of the Association of Southeast Asia Nations (ASEAN).

\section{The Current Disaster Management Architecture in Southeast Asia}

The extant disaster management architecture is a very sophisticated system. It basically constitutes three major components: national disaster management system, international relief agencies and their regional branches, and the regional relief agencies and initiatives under the framework of ASEAN.

The national disaster systems are created under clear political and judicial mandates. As they are usually endorsed by individual governments, the national systems, with few exceptions, possess the strongest mobilizing capacity, compared to the other two parallel systems. Specifically, different nations may adopt variable institutional structure to design their national disaster management systems. Some use the Stalinist design characterized by a separate permanent commission at the 
central government level and its administrative branches at the local level. The army, under certain circumstances, could be assigned at its disposal.

There is another common model in which no ministry-like agency exists in the central government, but instead, disaster management is in the charge of civil affairs ministries, which are mainly responsible for coordination. Yet, the absence of a strong governmental agency at the top level does not necessarily imply its weak capacity. On the contrary, many nations using this model actually enjoy a very robust grassroots capacity from their vibrant civil societies, a notable example being the Philippines.

When disaster comes, the performance of the self-organizing disaster relief efforts can be amazingly good. In spite of the varying institutional forms, the national disaster management systems undoubtedly have the strongest capacity to mobilize resources in most nations. Nevertheless, its shortcoming lies in the fact that the national disaster management systems, due to their sovereign and territorial attributes, are confined within the national borders and are not authorised to respond directly to disasters taking place in other countries despite the possible affinity. An even worse situation sometimes happens when authoritarian rulers refuse the external helping hand while its own system fails, which further deteriorates the devastation. This is actually what we occasionally witness within this region.

Natural disasters are quite peculiar because when they come, especially the bigger ones with immense destructive power, no matter how well the national systems are prepared, even the most powerful country in the world may need external assistance, not to mention the large majority of developing countries. Key players in the international arena include UN, WHO, UNESCO, IMF, World Bank, various international charitable organizations and most importantly, the Red Cross system. While some of them make their presence either on symbolic support and advocacy, or generous donations, the Red Cross Society has actually been the most reliable and professional agency in worldwide disaster relief endeavors. Despite the impressive record of the Red Cross parent and its national members, however, the Red Cross system has also been suffering, like most international giants, from bureaucratization and laggard responsiveness. A good example is its failure of immediate response to the 2004 Asian Tsunami. Whilst the tsunami took place on 26 December 2004 off the Sumatra coast, most relief headquarters were in their holiday season so that the emergent humanitarian assistance from the international organizations was allegedly delayed. Even the country offices of Red Cross Society within the region had to wait for the further assignment from the International Federation of Red Cross/Red Crescent, but hesitated to move forward within their discretion. In addition, the large amount of funding available among diversity of actors made coordination simultaneously more expensive and less effective (Christoplos 2006).

When it comes to the regional disaster management system, the entire picture becomes complicated. The current international humanitarian system has a very limited standby capacity, such as for airlifting. There is a missing link in joint planning and training between the military and traditional humanitarian actors. The absence of any agreed representative mechanism for NGOs has long been a constraint. Besides the regional offices of the above-mentioned international organizations, most regional disaster management organizations and initiatives are constructed under the 
ASEAN framework. With its ambitious vision of a disaster-resilient community by 2015, ASEAN has established several coordination centers and expert panels. The current major actors are shown in Table 1. The extant network seems very complicated and overlapping, which undermines the effective coordination.

Table 1 Coordination centers and expert panels of ASEAN

\begin{tabular}{ll}
\hline Name & $\begin{array}{l}\text { Founding Mandate } \\
\text { time }\end{array}$
\end{tabular}

time

Asian Disaster Reduction Centre (ADRC) 1998

ASEAN Regional Forum (ARF)

2002

Humanitarian Assistance and Disaster

Relief (HADR)

ASEAN Committee on Disaster

Management (ACDM)

ASEAN Ministerial Meeting on Disaster Management (AMMDC)

ASEAN Regional Program on Disaster Management (ARPDM)

ASEAN Agreement on Disaster Management and Emergency Response (AADMER)

Asian Disaster Preparedness Centre (ADPC)

ASEAN Coordinating Centre for Humanitarian Assistance (AHA)
1 Enhance disaster resilience of the member countries

2 Build safe communities, and create a society where sustainable development is possible

3 Enable ARF countries to function in a disaster area, and in co-operation with civilian relief organizations

4 Provide a common understanding and approach on managing the multiple and complex issues

5 Strengthen national and regional capacities in humanitarian assistance training

6 Understand the needs of and operational constraints affecting national agencies

7 Provide an opportunity for ARF participants to be trained and to interact in the area of humanitarian and disaster relief operations

20038 Assume overall responsibility for coordinating and implementing the regional activities

9 Review and enhance regional cooperation on disaster management. Share national experiences and further strengthen regional cooperation

200410 Cooperate among member countries, capacity building, sharing of information and resources,

11 Engage external partnerships, and public education, awareness and advocacy

200512 Provide an effective mechanism to achieve substantial reduction of disaster losses in lives and in the social, economic and environmental assets of the Parties

13 Respond jointly to disaster emergencies through concerted national efforts and intensified regional and international cooperation

200514 Facilitate the creation of an early warning system for tsunamis and other natural disasters in the Indian Ocean and Southeast Asia

200815 Facilitate cooperation and coordination among the Parties, and with relevant UN and international organizations, promote regional collaboration 


\section{An ASEAN Disaster Relief Centre}

So as to find a solution to the problems identified above, we propose a regional disaster response institution under the umbrella of the ASEAN. This institution could tentatively be called "Disaster Response Training and Logistic Centre" (the Centre) As North (1991) defines it, the institution is devised to structure political, economic and social interaction including enforcement characteristics. The Centre is an ad hoc virtual relief institution which enforces mitigating the risk and the effects of disasters, providing accurate pre- and post-disaster relief assessment on the ground, providing training for disaster relief teams in ASEAN on a regular basis, and allocating and mobilizing relief aid. In addition, the Centre will be endorsed by all ASEAN governments and will operate and report directly to the Secretary General of the ASEAN Secretariat. The philosophy underpinning the establishment of this organization reflects a different approach from current disaster relief efforts. Given the political complexity and racial and cultural diversity in Southeast Asia, stronger government involvement and regional integration in disaster relief is indispensable.

The Centre is a subordinate statutory organization under the General Secretariat of ASEAN. The Centre will liaise with the AHA on matters of disaster management and coordinate with external constituencies such as international non-governmental relief organizations (Red Cross, Medicine Sans Frontier, etc.), civil society organizations (e.g. human rights advocates), industries (e.g. pharmaceuticals, business enterprises) and governmental organizations (e.g. UN Office for the Coordination of Humanitarian Affairs). The internal organizational structure of the Centre-DRTLC - is contingent to disasters (see Figs. 3, 4). Under the Centre, there is a director and a secretariat-general (SG) in charge of administration and

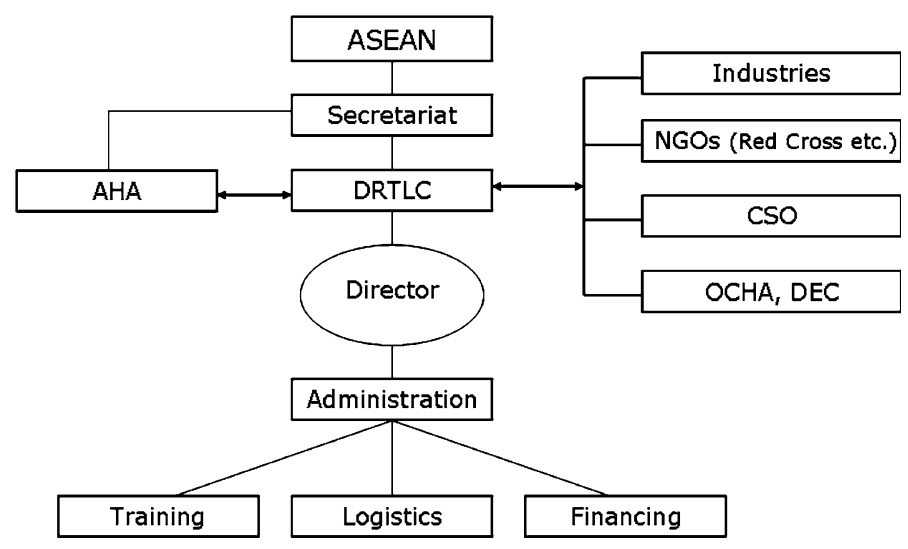

Fig. 3 Proposed organization chart of DRTLC. Legend: DRTLC Disaster Response, Logistic and Training Centre, ASEAN Association of Southeast Asian Nations, AHA ASEAN coordinating centre for humanitarian assistance on disaster management, $N G O s$ non-governmental organizations, CSO, civil society organization, $O C H A$ office for the coordination of humanitarian affairs, $D E C$ Disaster Emergency Committee 


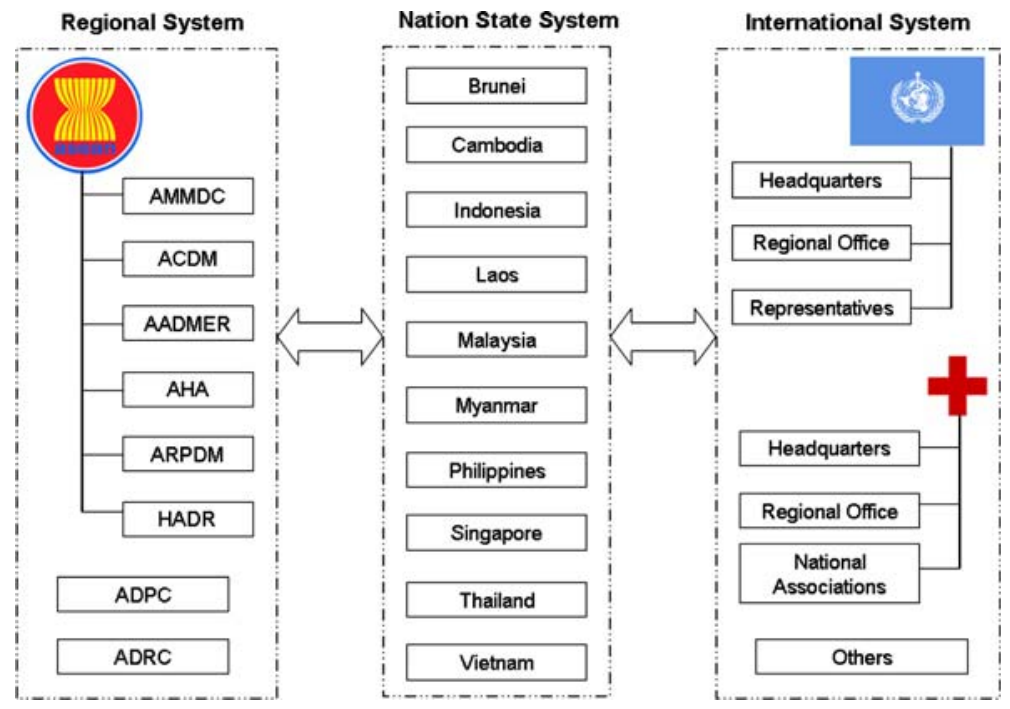

Fig. 4 Interplay between different actors in humanitarian relief in ASEAN

coordination. Further subdivisions of Logistics, Training and Financing are distinctly established under the SG and equipped with specialized duty for operation in this virtual organization. The Centre and the Administration Office is a standing operation unit while the three subdivisions are complementary and contingent to the Centre. How each subdivision works will be illustrated in the following six functions of the Centre.

The Centre will serve, but not be limited to, the following six functions:

Response: Quality Improvement of Disaster Response by Assessment and Evaluation

The Centre is situated in position to better estimate and rank aid priorities based on the accurate assessment of local needs. The Administration Office under the Director appoints the assessment team, composed of state representatives and expert panel, to legally oversee, and communicate with, the reciprocal extant relief network in each state member, respectively. The mandate of the Administration Office is to provide a landmark assessment report based on thorough analysis of preparedness and gaps in implementing the relief network, such as Hyogo Framework. In addition, the Administration Office provides risk identification at all levels and scales. Moreover, the Centre will serve as the ASEAN legitimate body to assert leverage on the civil-military coordination in which it calls for greater engagement between civil and military actors in response in disaster relief (Harkin 2006). In this role, not only will the Centre coordinate relief operations among Divisions of Training, Logistics and Financing, but its expertise and capacity will exert the greatest impact on the overall relief 
operations. Evaluation during and after the relief work reflects and warrants the quality of each humanitarian assignment. Apart from preparing routine assessment through periodic reviews of progress on a regular basis and timely emergent assessment right after disaster, relief work evaluation coordinated by the Centre aims to improve the quality of disaster relief, thereby inculcating betterment in both the daily disaster preparedness phase and in the recovery and rehabilitation phase. The evaluation process per se will hold the relief agencies on the ground accountable and provide evidence for subsequent research and development, reference for training content, rationale of logistic operation, and database of relief informatics.

\section{Logistics: Provision of Logistic Network for Better Coordination of Relief Resources}

The current disaster relief management system has limited capacity for coordination between relief agencies. Given this, the Centre will provide a logistic network that will maximize efficiency and effectiveness when delivering relief aid. Based on the accurate, reliable assessment report in the field and of reciprocal capacity reserve, the Logistics Division is designed to coordinate the mobilization, allocation and distribution of the relief resources. These resources compose human resources (e.g. experts, military forces, relief construction workers, volunteers, non-governmental organizations, civil societies, industries), and physical resources (e.g. tarpaulins, materials for building shelters, mosquito nets, blankets, and towels, water purification tablets and bottled water, kitchen and cooking sets, surgical masks, gloves and first-aid kits). The Division in the operation plan seeks to cooperate with four leading industry players in the Logistics and Transportation Industry Humanitarian Workstream (LTHW) through a public-private partnership (PPP), which will be discussed later. Included in this logistic network is a common pool consisting of stocktaking and stockpiling logistics on trends in disaster risks and progress on disaster risk reduction. The common pool has a 3-day reserve capacity of relief durable goods at its discretion. To keep the affluent flow of viable relief material in the pool, the Logistics Division relies much on mutual information provision and sharing monthly reserve capacity of national stockpiling in each member state. The Logistics Division is set up to increase the readiness of relief agencies (stocktaking) to deliver aid after disaster strikes within the first $72 \mathrm{~h}$ - the "golden hours" when aid (stockpiling) is most critically needed. Moreover, because the Centre is totally transparent to all stakeholders and the governments of disaster-affected states, accountability within the Centre can therefore be strengthened and secured. More substantially, the Centre aims to effectively mobilize and direct relief personnel to the disaster-affected region, expedite work permit and visa applications for relief workers, and facilitate freedom of access and freedom of movement in disaster areas. The country to accommodate the Logistics Division needs to consider its strategic position where mobilization of resources can be operated in a transparent and effective way. Singapore is the place of choice for the time being. 
Training: Provision of Training to Link Relief, Rehabilitation and Development Operations

As is stated in the Hyogo Framework for Action, it is imperative to strengthen local and national preparedness on a daily basis. However, few countries have made substantial progress toward the priorities. According to a report by UNDP in 2004, the area of underdevelopment is the most vulnerable on account of the majority of death toll (UNDP 2004). This underscores the importance of training in building up the adequate and optimal capacity reserve. The lack of capacity during disaster relief operations and the subsequent recovery stage is another surmountable problem that the Centre will address. The Training Division of the Centre is designed to strengthen local and national capacity by providing training to those Southeast Asian countries and civil society groups that are less able to cope with disasters. After reviewing the extant training programmes within the region, the Training Division aims to coordinate with its allied national branches to provide tailored training programmed periodically based on the commensurate reality check of the assessment report, which is subject to individual prerequisites in each disaster prone area. The Training Division entails enlisting human resources, such as extant relief experts, relief network and agencies, voluntary welfare organizations, and so on. The Division thus is well placed to perform its functions since it possesses the skills, technology and expertise to plan and effectively implement appropriate programs. Beyond its training function, the Centre will also retain a role for providing certification and accreditation in that it will monitor and require relief agencies to ensure that their staff are qualified on the common ground and competent before being assigned to a relief operation. The Training Division cooperates with the Logistic Division by providing accurate data of priority qualified relief personnel/agencies for more effective mobilization. Voluntarism should go along with professionalism in humanitarian assistance. The Training Division has engendered much credibility to quality relief work in which it overarches effective governance. Rehearsing and practicing what has been preached in the simulated scenario is another core function the Training Division serves. The simulated scenario workshop needs to accommodate contextual and cultural nuance in disaster-prone countries, so the Training Division should have outreach local posting collaborated with Thailand, Indonesia and Myanmar. In this way, not only can the Centre realize and do its upmost to fill the gaps in implementing risk reduction, but as well link relief with rehabilitation and development operations. However, training and logistics alone cannot perfect the sustainable operation without shared responsibility, i.e. partnership.

\section{Partnership: Establishment of a Public-Private Partnership Framework}

The weakness of existing disaster relief management system points to the absence of effective coordination between public and private sectors. Whilst the private sector has been generous in providing humanitarian assistance, the extant relief network has limited the corporate response to disaster emergencies, thus undermining the overall effectiveness and efficiency. One innovative approach is to build a PPP 
Table 2 Opportunities for private sector engagement in humanitarian relief

\begin{tabular}{|c|c|}
\hline Industry & Opportunities for engagement \\
\hline Logistics and transport & $\begin{array}{l}1 \text { Warehousing and transport services } \\
2 \text { Specialized logistical and transport staff: airfield specialists, warehouse } \\
\text { managers }\end{array}$ \\
\hline $\begin{array}{l}\text { Engineering and } \\
\text { construction }\end{array}$ & $\begin{array}{l}3 \text { Temporary and permanent infrastructure reconstruction, homes, roads, } \\
\text { electricity generation facilities, hospitals, schools, etc. } \\
4 \text { Specialized water/sanitation services: water and sanitation system development } \\
5 \text { Specialized shelter, recovery, and water/sanitation-related staff: architects, } \\
\text { civil engineers, hydrogeologists }\end{array}$ \\
\hline $\begin{array}{l}\text { IT/ } \\
\text { telecommunications }\end{array}$ & $\begin{array}{l}6 \text { Radio and mobile phone systems } \\
7 \text { Internet/connectivity systems: satellite, radio, LANs } \\
8 \text { Specialized telecommunications and IT staff } \\
9 \text { Specialized information systems: supply chain management software, } \\
\text { nutritional assessment and surveillance systems }\end{array}$ \\
\hline Healthcare & $\begin{array}{l}10 \text { Medical supplies } \\
11 \text { Public health education equipment } \\
12 \text { Specialized medical staff, infectious disease experts, women's health } \\
\text { practitioners }\end{array}$ \\
\hline Retail & 13 General household items: blankets, cooking utensils, etc. \\
\hline Food and beverage & $\begin{array}{l}14 \text { Therapeutic feeding supplies and other relevant food supplies: fortified foods, } \\
\text { micro-nutrients, cooking suppliers } \\
15 \text { Agricultural support: seeds and tools } \\
16 \text { Specialized recovery-related staff: agricultural engineers }\end{array}$ \\
\hline Energy & 17 Fuel: vehicle and aircraft \\
\hline Financial services & $\begin{array}{l}18 \text { Micro-credit: grants and loans } \\
19 \text { Specialized recovery-related staff: small business advisers, credit officers }\end{array}$ \\
\hline Professional services & $\begin{array}{l}20 \text { Management and negotiation training/support } \\
21 \text { Legal services } \\
22 \text { Specialized management and protection-related staff: project managers, } \\
\text { security experts, lawyers }\end{array}$ \\
\hline Media & $\begin{array}{l}23 \text { Public relations services } \\
24 \text { Specialized PR staff, media management experts, print and TV }\end{array}$ \\
\hline
\end{tabular}

Source: Humanitarian Relief Initiative, World Economic Forum 2005, 2008-10-27, http://www.weforum. org/en/initiatives/HumanitarianReliefInitiative/index.htm

framework originally advocated by Humanitarian Relief Initiative (HRI) where the Disaster Resource Network (DRN) focuses on the civil infrastructure dimensions of disaster response and preparedness (Table 2). The PPP framework aims to strengthen the integrity of the disaster-affected community, raising awareness of operational needs, leadership in self-governance, and socialization via collective participation. The Centre proposes a merit-based registration system to embody the PPP framework in its main functions, such as training and logistics. The registration system is based on the track record of the private sector's involvement and performance in the prior relief work. Feedback from victims of the affected locality 
and evaluation report by the expert panel will be graded as a reference for credibility of the private sector involving in priority construction work at the response, recovery phase and subsequent developmental phase. Based on the agreement on procedures and criteria for collaboration, the private sector is incentivized to take part in the relief work shared with the public authority. The check and balance in the relationship will not only ensure the cost-effective work but hold the corporate socially responsible in building a resilient community. The housing project along with community socialization partnered by Habitat for Humanity Indonesia exemplifies the best practice. This is the way how the PPP joint efforts can harmonize diversified relief operations to build up ownership of sustainable development.

\section{Ownership: Strengthening of Local Capacity}

The best way to reduce risk of future disasters is that vulnerable people start to take control of their environment and build sustainable partnerships with international actors (Scheper et al. 2006). The SPHERE Project has pointed out that the long-term benefits realized during the course of strengthening local capacities to deal with disasters and relief work should support and/or complement extant services and local institutions (SPHERE Project 2004). For example, CARE International in the 2004 Tsunami, through asset replacement, has helped the survivors rebuild their farms and businesses with the skills they need to increase their income and expand their knowledge. The Centre calls for full engagement of each state member in the design, assessment, monitoring and evaluation of humanitarian response and the strengthening of the capacity. The Administration Office is to identify the gap of preparedness in each country and to provide adequate training programmes to risk reduction. The Center maximizes its effectiveness in each country with its extensive networks of representative delegates. The Centre will start as a regional collaboration in which official representatives from each state member are required to provide an acknowledged format of key information related to disaster preparedness in their own country (e.g. response network, relief mechanism and contingency plan) that will then be collated into a common database pool of capacity reserve that may be accessed by affiliated relief agencies. This is the way whereby nuance of individual context will be recognized, respected and local capacity will be timely mobilized by the relief agencies. In addition to supporting national and local capacity, poor understanding and communication among relief agencies of location-specific drivers of recovery can often complicate disaster relief operations. Information is the key overarching the aforementioned functions.

\section{Information: Provision of Transparency and Predictability in Relief Responses}

A key weakness of the present disaster management system is that the validation, compilation and dissemination of raw disaster-related intelligence are conducted at the national level (as opposed to the transnational level). As a result, there is a clear absence of coordination between governments. Since the Centre serves as an overall coordinator of relief operations, it will have more access to better disaster-related 
intelligence. In order to integrate the aforementioned functions, reciprocal information sharing is very important. Information of assessment, resources, donor and recipient capacities reserve, and existing response networks can serve to guide the strategic interactions and productive exchange among different stakeholders such as public officials, policymakers, private business and international organizations (Ahrens and Meurers 2002). Given the legal and regulatory framework of ASEAN, the flow of information will allow the Centre to act as an information processing hub for cooperative and coordinated relief responses and ensure a transparent assignment of tasks according to comparative advantages of each stakeholder and make policy action predictable. Moreover, clear relief rules and criteria of relief competencies would also enhance the accountability of each relief actor. By providing and receiving information, the Centre aims to bring together all stakeholders and reduce transaction costs as well as information asymmetries. With its established communication channels, the Centre is able to communicate immediately with disaster-stricken governments as well as disseminate critical information to the appropriate authorities.

This section provided an overview of the functions and organizational roles the Centre. The most significant aspect of this centre is the role that it plays in coordinating relief operations and logistical support, collating and disseminating disaster-related information, and the training of disaster relief personnel. Given this inadequacy of the current disaster relief management system in place in Asia, the Centre will definitely enhance the effectiveness of disaster relief in disaster-prone Southeast Asia. Ultimately, the creation of the Centre will guarantee that more lives will be saved in the event of a disaster.

\section{Global Governance Towards Regional Approach}

As we improve our understanding of governance, especially in the field of disaster management, it should become obvious that the dynamics between good governance and mitigating the social cost of disasters are interrelated. Indeed, finding an optimal balance between economic growth and ecologic sustainability has become a key issue of our generation. In other words, notions of global governance and best practices are no longer abstractions but substantive issues that need active policy actions to realize.

At the same time, the need to reconcile traditional notions of sovereignty with new ideas such as humanitarian intervention has gained greater urgency in the aftermath of recent devastating disasters in Asia. Certainly, the refusal of the military junta in Myanmar to accept foreign assistance in the aftermath of Cyclone Nargis tested the limits of state sovereignty. The case also raised important legal questions over the state's right to claim sovereignty when it lacks the capacity to govern. This is a critical area for future research by legal theorists and policy scholars.

To achieve the key tenets of global governance-transparency, effectiveness, efficiency and accountability-there are some key lessons and core principles that could be learnt as our understanding of disaster management improves. If there is a 
silver lining to disasters, it is that human understanding tends to improve over time. The key lessons and principles drawn from this research project are:

- Disaster mitigation must come first. Even though national interest and security concerns are important, humanitarian assistance should not be considered as peripheral to them.

- Impartiality and neutrality must be maintained. In order to maintain impartiality, there is a need to establish the moral high ground and this can be achieved by respecting other cultures, and overcoming the social, political, and religious biases that cloud human judgment.

- Encourage equal partnership and ownership. This can be attained by treating disaster victims with integrity even though this may be slow down the process of relief work. But this problem can be overcome effectively if foreign relief agencies work closely with local government and local groups.

- Enhance local capacity to absorb foreign assistance. This principle is extremely important since disaster-affected countries will continue with the rebuilding process even when foreign relief workers are gone. Therefore, in addition to aid delivery, local capacity to rebuild must also be raised. Indeed, disaster-affected countries must bring in some of their own human capital so that they can absorb the technology and expertise brought in.

\section{Conclusion}

To deal more effectively with future disasters in Southeast Asia, it is critical that ASEAN develop the political will to implement a disaster management system that is holistic. This disaster management system should emphasize planning, strategic mobilization, better preparation, training for relief project workers, and the mechanisms to push aid through unresponsive governments. Indeed, clear protocols for systematic actions by different relief agencies will lead to more efficient and effective relief operations.

Because poorer countries may lack the capacity to rebuild and sustain a recovery, a well-design exit strategy is thus of great importance. Certainly, it is imperative that each country outlines the means by which the recovery effort can remain sustainable after the exit of foreign relief workers. To ensure the sustainability of the recovery effort, participation and ownership by local communities and groups are indispensable. Indeed, encouraging active community involvement in the recovery process is an internationally accepted principle in disaster recovery management and Wickramage (2007) found that engaging communities early in the recovery process is necessary to prevent "aid-mediated" communal tensions. Therefore, changing the mindset of the local people must be the core of relief work.

At the same time, a sustainable plan at a minimum should include a description of how relief operations will be maintained over time (including an examination of how quality will be maintained, and the amount of resources necessary). A key mechanism that enhances effective disaster relief is the PPP framework. This partnership has been widely adopted especially for housing reconstruction with the 
government responsible for providing land and basic infrastructure while civil society organizations are responsible for providing resources for the actual construction process.

This research also found that better informational exchange and sharing is critical for effective disaster relief since it facilitates the sharing of expertise, the transfers of information and resources that are not available in the public domain, and peerto-peer organizational relief and support beyond traditional donor networks.

Acknowledgments The authors are very grateful to staff of various international relief organizations who shared their expertise and valuable insights with generosity when they were preparing the early draft as well as their critical comments on the final article. His emotional support always inspires junior scholars to move forward. The authors also thank Dean and the management of the Lee Kuan Yew School of Public Policy for kindly offering generous financial support.

\section{References}

Ahrens J, Meurers M (2002) How governance affects the quality of policy reform +and economic performance: new evidence for economies in transition. J Inst Innov Dev Transit (IB Review) 6

Australia Emergency Manual Disaster Recovery (1996) Canberra: Emergency Management Australia

Christoplos I (2006) Links between relief. rehabilitation and development in the tsunami response, Tsunami Evaluation Coalition, London

Fisher D (2007) Domestic regulation of international humanitarian relief in disasters and armed conflict: a comparative analysis. Int Rev Red Cross 89:866

Harkin C (2006) Coordination of international humanitarian assistance in tsunami-affected countries: the 2004 tsunami: civil military aspects of the international response. Tsunami Evaluation Coalition, London

International Federation of Red Cross and Red Crescent Societies (2005a) World Disaster Report 2005, 2006-03-09, http://www.ifrc.org/publicat/wdr2005/index.asp

International Federation of Red Cross and Red Crescent Societies (2005b) Code of conduct: The International Red Cross and Red Crescent Movement and NGOs in Disaster Response Programs

Mangkusubroto K (2005) The route to a modern Indonesia: rebuilding from zero (public lecture) Singapore, August 31, 2005

North DC (1991) Institutions. J Econ Perspect 5(1):97-112

Overseas Development Institute (1996) Joint evaluation of emergency assistance to Rwanda: study IIIprincipal findings and recommendations June 18-21

Rowlands A, Ngoh T, Yuen K (2006) Preface: contribution of social work to recovery and rehabilitation after the Asian tsunami disaster. In: Rowlands A, Ngoh T, Yuen K (eds) Asian tsunami and social work practice: recovery and rebuilding. The Haworth Press, Binghamton, pp xix-xxv

Scheper E, Parakrama A, Patel S, Vaux T (2006) Impact of the tsunami response on local and national capacities. Tsunami Evaluation Coalition, London

SPHERE Project (2004) Humanitarian charter and minimum standards in disaster response (2004 edn). SPHERE Project, Geneva

Tay KT, Paige JT (2006) With the best of intentions: Singapore volunteers and donors and the tsunami reconstruction. J Soc Work Disabil Rehabil 5(3/4):97-108

UNDP (2004) Reducing disaster risk: a challenge for development. United Nations Development Programme, New York

Weinstein HM, Fletcher LE, Stover E (2007) Human rights and mass disaster: lessons from the 2004 tsunami. Asia Pac J Public Health 19:52-59

Wickramage K (2007) Hands in relief, eyes on development: challenges and community responses in the delivery of humanitarian aid in conflict affected and tsunami ravaged districts in northern Sri Lank. Asia Pac J Public Health 19:25-34 